\title{
Ensino em Tempos Tecnológicos: Olhares e Percepções de Mestrandos em Formação
}

\author{
Enseñanza en Tiempos Tecnológicos: Miradas y Percepciones de \\ Mestrandos en Formación
}

Teaching in Technological Times: Views and Perceptions of Master's Students

\author{
Rogério José Schuck ${ }^{1}$ \\ Adriano Edo Neuenfeldt ${ }^{2}$ \\ Silvana Neumann Martins ${ }^{3}$
}

\begin{abstract}
Resumo
Com a chegada de novas ferramentas tecnológicas de comunicação e informação, o uso da internet ganhou destaque e aumentou significativamente a velocidade com que se dá o acesso às informações. Nesse cenário, a iniciação à pesquisa pode ser beneficiada e potencializar a construção do conhecimento. $\mathrm{O}$ estudo buscou investigar processos de ensino, de iniciação à pesquisa e de aproximação com as Tecnologias Digitais de Informação e Comunicação - TDIC, que permeiam as práticas pedagógicas de docentes do Ensino Superior e da Educação Básica. Foram entrevistados seis alunos mestrandos que desenvolvem seu trabalho nas regiões Sul, Norte e Nordeste do Brasil. Trata-se de uma pesquisa qualitativa, sendo que as informações foram coletadas mediante entrevista gravada, seguindo um roteiro de questões semiestruturadas. Resultados apontam que todos os alunos mestrandos trazem uma predominante concepção de que as pesquisas devem ser realizadas na biblioteca da escola ou então na sala de informática, sendo que justificam o não fazer pesquisa pela falta de infraestrutura. A ideia de realizar investigações/pesquisas na sala de aula é algo distante da compreensão da maioria dos entrevistados.
\end{abstract}

Palavras-Chave: Aprendizagem; Ensino; Docência; Iniciação à pesquisa; TDIC.

\section{Resumen}

Con la llegada de nuevas herramientas tecnológicas de comunicación e información, el uso de Internet ganó destaque y aumentó significativamente la velocidad con que se da el acceso a la información. En este escenario, la iniciación a la investigación puede ser beneficiada y potenciar la construcción del conocimiento. El estudio buscó investigar procesos de enseñanza, de iniciación a la investigación y de aproximación con las Tecnologías Digitales de Información y Comunicación - TDIC, que permean las prácticas pedagógicas de docentes de la Enseñanza Superior y de la Educación Básica. Se entrevistaron seis alumnos de maestrandos que desarrollan su trabajo en las regiones Sur, Norte y Nordeste de Brasil. Se trata de una investigación cualitativa, siendo que las informaciones fueron recolectadas mediante entrevista grabada, siguiendo un guión de cuestiones semiestructuradas. Los resultados apuntan que todos los alumnos de maestría traen una predominante concepción de que las investigaciones deben realizarse en la biblioteca de la escuela o en la sala de informática, justificando el no hacer investigación por la falta de infraestructura. La idea de realizar

\footnotetext{
${ }^{1}$ Doutor em Filosofia; PPGENSINO E PPGECE - Univates; Lajeado, RS, Brasil; rogerios@ univates.br. Trabalho apresentado no III Encontro Humanístico Multidisciplinar e II Congresso Latino-Americano em Estudos Humanísticos Multidisciplinares - Jaguarão, RS, Brasil, 2017.

${ }^{2}$ Mestre em Educação; Doutorando em Ensino; PPGENSINO - Univates; Lajeado, RS, Brasil; adrianoneuenfeldt@univates.br.

${ }^{3}$ Doutora em Educação; PPGECE e PPGENSINO - Univates; Lajeado, RS, Brasil; smartins @ univates.br.
} 
investigaciones / investigaciones en el aula es algo distante de la comprensión de la mayoría de los entrevistados.

Palabras claves: Aprendizaje; Enseñanza; Docência; Iniciación a la investigación; TDIC.

\begin{abstract}
With the emergence of new technological tools of communication and information, the use of the internet has gained prominence and significantly increased the speed to access information. Within this setting, initiation to research might be benefitted and optimize construction of knowledge. This study aimed at investigating teaching processes, of initiation to research and of approach to Digital Technologies of Information and Communication (DTIC) that integrate the teaching practices of teachers and professors of Basic and Higher Educations. Six master's degree students who work in Southern, Northern and Northeastern Brazil were interviewed. It is a qualitative research, with information collected through recorded interviews, following a script with semistructured questions. Outcomes show that these master's degree students share a prevailing view that research has to be carried out in the school library or in the computer room, and they justify not doing it due to the lack of infrastructure. For most of the interviewees, investigating/researching in the classroom is something far from their understanding.
\end{abstract}

Keywords: Learning; Teaching; Initiation to research; DTIC.

\title{
1. Introdução
}

O presente texto surge a partir de uma pesquisa vinculada a dois Programas de PósGraduação Stricto Sensu, na área do ensino, da Universidade do Vale do Taquari - Univates. Neste estudo, buscou-se investigar como está sendo desenvolvida a iniciação à pesquisa e o ensino junto a alunos mestrandos que trabalham nas regiões Sul, Norte e Nordeste, bem como percepções que os investigados estão tendo diante do contexto contemporâneo em relação à pesquisa em sala de aula e como esta questão está impactando no ensino. Nesse sentido, estamos falando a partir da formação da subjetividade dos sujeitos em tempos permeados pelas tecnologias, sendo que o estudo buscou a aproximação com processos de ensino e de aprendizagem com as Tecnologias Digitais de Informação e Comunicação - TDIC.

Vivemos tempos de profundas e rápidas mudanças. Neste cenário, de aceleração constante, de informações "de natureza torrencial ou oceânica” (LÉVY, 1994, p. 86) o indivíduo se vê envolto num contexto de crescente complexidade em relação à apropriação do conhecimento. Compreender o atual momento educacional exige a capacidade de relacioná-lo com os conceitos temporais e sociais que o envolvem. O grande desafio que se coloca está em conceituar o tempo e o instante na tentativa de uma compreensão do momento e que essa nos permita um entendimento do contexto escolar em termos de pesquisa e utilização das Tecnologias Digitais de Informação e Comunicação - TDIC.

Lévy (2001) é categórico ao afirmar que é esta capacidade humana de conectar-se através das redes e das TDIC que propiciou a "conexão planetária". Vivemos conectados, ligados umbilicalmente por meio de nós e das redes. Conforme Lévy (2001, p. 33) "precisamos olhar o mundo de hoje com os olhos do mundo de amanhã, não com os do 
mundo de ontem. Ora, os olhos de amanhã são os olhos planetários. As fronteiras são as ruínas, ainda de pé, de um mundo em revolução". Mas, o que são as fronteiras senão metáforas criadas por nós seres humanos? Para Pesavento (2008), as fronteiras são marcos culturais e simbólicos criados por nós. São como portas ou janelas que, na sua dualidade, permitem ou impedem a entrada e a saída. Segundo a autora, "fronteiras limitam, encerram e fecham, negam o diálogo e o contato, tal como podem abrir, comunicando e aproximando as partes, criando laços, correspondências, percursos de vida em paralelo, convergências, oposições e competição" (PESAVENTO, 2008, p. 179). Sendo criação humana, as fronteiras também são passíveis de modificações, transformações ou mesmo podendo vir a ser totalmente eliminadas.

Vivemos a aurora do rompimento de fronteiras. Para Lévy (2001), pouco a pouco, a humanidade encaminha-se para o desaparecimento dessas, não só em termos econômicos e comerciais - essas, de certa forma, já nem existem mais - mas também em termos de transitoriedade do ser humano e tudo a que ele diz respeito. O próprio ser humano aparece nesse cenário como um ser que transcende fronteiras. Neste aspecto, o autor enfatiza que o ser humano é uma duração de existência e que, à base de suas experiências, participa do todo. Significa dizer que o ser humano é uma alma sem nacionalidade, pois, "todas as almas têm uma única pátria espiritual. $\mathrm{O}$ corpo não tem nacionalidade. Todos os corpos têm uma única humanidade. Não somos de um país, somos de um período do espírito humano" (LÉVY, 2001, p. 35).

Neste novo cenário, estamos constantemente sendo interpelados a sair da zona de conforto, pois constatamos que somos "nómadas perseguindo o futuro humano, um futuro que nos perpassa e que nós fazemos. O humano tornou-se o seu próprio clima, uma estação infinita e sem retorno" (LÉVY, 1994, p. 18). Marchamos rumo ao desconhecido, por espaços e tempos que causam estranheza, tornando-nos seres errantes em busca de espaços cibernéticos desconhecidos. Mesmo estando a sós, não estamos sozinhos, pois estamos acompanhados de babeis digitais, de um enorme emaranhado de redes a abrir o tempo e o espaço para novas possibilidades.

Vivemos tempos de novos horizontes que se abrem nesse processo de reconciliação. Somos os astronautas de novos espaços, capazes de navegar entre galáxias virtuais sem sair de nossos lares. Participamos de múltiplos espaços, outros espaços, não na atmosfera e muito menos na estratosfera, mas sim no ciberespaço, na noosfera (LÉVY, 2001). Ao passarmos por tais espaços, por devires, tornamo-nos internautas, cibernautas. 


\section{Procedimentos Metodológicos}

A pesquisa seguiu uma metodologia qualitativa, na qual, conforme Bogdan e Biklen (1994), os dados recolhidos são denotados por qualitativos, pois são minuciosamente descritivos em relação aos sujeitos da pesquisa e as entrevistas. Por isso trata-se de um estudo descritivo, que busca descrever os dados e informações que obtivemos, seguindo o método de abordagem indutivo.

Fizeram parte da população investigada seis alunos, do Mestrado em Ensino de Ciências Exatas e do Mestrado em Ensino, da UNIVATES, e que trabalham na região Sul, Norte e Nordeste do Brasil. Cinco mestrandos possuem licenciatura plena, três deles na área de Ciências Exatas, dois possuem graduação em Pedagogia, sendo um deles também formado em Educação Física. Três foram bolsistas, dois de iniciação científica e um de um programa do Conselho Nacional de Desenvolvimento Científico e Tecnológico - CNPq, sendo que todos possuem experiência na Educação Básica e três atuam na docência, junto à graduação.

O instrumento de coleta de dados utilizado junto aos mestrandos foi uma entrevista semiestruturada, realizada pela equipe de pesquisadores. A análise dos dados ocorreu durante o processo de estudos, simultaneamente com a sua coleta. As informações obtidas através das entrevistas foram tabuladas e interpretadas, reunidas em categorias de análise. A partir daí buscou-se compreender e verificar semelhanças e explicar divergências nas entrevistas. $\mathrm{O}$ tratamento das informações seguiu as orientações da análise textual discursiva (MORAES; GALIAZZI; 2013), que prevê a desconstrução dos textos e a consequente organização em unidades de análise ou unidades de sentido ou de significado.

Cabe destacar que o nome dos alunos mestrandos que participaram da pesquisa não foram divulgados, garantindo o anonimato das informações obtidas, assim como das instituições de ensino envolvidas, com exceção da proponente. Todos os sujeitos da pesquisa consentiram livremente, através da assinatura do Termo de Consentimento Livre e Esclarecimento (TCLE), a sua participação na pesquisa. Os sujeitos entrevistados foram denominados de M1 (Mestrando 1), M2 (Mestrando 2) e assim sucessivamente. Os resultados das entrevistas foram organizados em três categorias, conforme apresentado a seguir.

\section{Análise e discussão dos resultados}

Os dados que emergiram a partir das entrevistas realizadas, oportunizaram a criação de duas categorias, a saber: Pesquisa na sala de aula e Aproximações com as Tecnologias Digitais de Informação e Comunicação, conforme segue abaixo. 


\subsection{Primeira categoria: Pesquisa em Sala de Aula}

Conforme Moraes, Galiazzi e Ramos (2012) ao pesquisar em sala de aula, o professor novamente reforça a convicção de que: "Envolver-se nesse processo é acreditar que a realidade não é pronta, mas se constitui a partir de uma construção humana" (Ibidem, p. 10). Corroborando com esta ideia, o entrevistado M1 comentou: "eu fiz uma pesquisa com os impostos, foi a única pesquisa que eu consegui desenvolver esse ano". Comenta a possibilidade de desenvolver esse trabalho apenas durante a sua hora/aula: "eu posso ir desenvolvendo essa pesquisa e ela não me tira digamos assim, da minha hora aula, da minha aula que eu tenho que dar o conteúdo curricular que apresento" (M1). Podemos perceber a preocupação do entrevistado em relação à sua atividade docente, sendo que a investigação realizada aparece como algo desatrelado do dia a dia da atividade de sala de aula, como algo outro, ou a mais, que o docente realiza além da sala de aula.

Na mesma linha de raciocínio, o entrevistado reconhece a importância da pesquisa, mesmo mantendo-a vinculada ao espaço fora da sala de aula: "e daí eu fiz eles pesquisarem fora da sala, coisas assim como IPTU, IPVA" (M1). O início desta atividade contou com a participação de outro professor: "tinha um professor de Seminário Integrado [...] que especificou os passos de como fazer pesquisa, porque esses alunos precisavam entender o suporte da pesquisa" (M1). A experiência com relação à iniciação à pesquisa aparece desatrelada da descrição do que o professor compreende como sendo a aula, que deve acontecer no espaço formal de uma sala de aula. Com isso, evidencia-se que a questão da investigação e do ensino, ainda são tratados e pensados como sendo dois momentos distintos na vida do docente.

Cabe aqui salientar que o Seminário Integrado, mencionado pelo entrevistado M1, está inserido no contexto escolar das escolas públicas estaduais do Rio Grande do Sul, desde a implantação do Ensino Médio Politécnico, no ano de 2012. Um dos princípios do Ensino Médio Politécnico é a pesquisa como princípio educativo (RIO GRANDE DO SUL, 20112014) e a pesquisa é o processo que, "integrado ao cotidiano da escola, garante a apropriação adequada da realidade, assim como projeta possibilidade de intervenção. Alia o caráter social ao protagonismo dos sujeitos pesquisadores" (Ibidem, p. 20).

Ao ser questionado sobre a realização de pesquisas em sala de aula, M2 respondeu que "Como professor, não". Quando falou sobre a importância da iniciação à pesquisa, relatou levar os alunos ao laboratório de informática: "Mas eu creio que, os laboratórios, de um modo geral, hoje, ligados a ciências ou ligados a matemática, ele é um grande aliado para o desenvolvimento desse currículo, dessa aprendizagem" (M2). É possível identificar certa 
dificuldade em refletir sobre a efetividade das ações de investigação, por parte do entrevistado M2, pois o mestrando acaba restringindo seu espaço de pesquisa ao laboratório de informática.

O mestrando M3, em contraponto a M2, desenvolve pesquisas em sala de aula: " $a$ gente tá com um projeto de iniciação à pesquisa, na verdade, e a gente tá fazendo passo a passo com os alunos da educação básica como se faz uma pesquisa”. Colocou que seu trabalho se dá através de projetos: "eu crio um projeto para as questões que surgem na sala de aula" (M3). Além disso, desenvolve com os alunos gráficos e tabelas: "eles construíram gráficos, eles fizeram a tabulação" (M3). Para ele, o professor também precisa estar desenvolvendo o trabalho através de leituras: "maior leitura por parte do professor" (M3).

$\mathrm{Na}$ mesma linha de raciocínio, mas voltando a atenção mais para questões formais, o entrevistado M4 desenvolve pesquisa com seus alunos ao final do ano letivo: "todo semestre eu concluo com uma atividade de pesquisa orientada". Ele compõe essa atividade em duas partes: "vou com eles pro laboratório verificar a questão da formatação de slides e depois disso, eles saem a campo, depois de toda uma orientação teórica" (M4).

Para M5 as pesquisas que desenvolveu surgiram a partir do interesse dos alunos, como nesse caso: "um aluno chegou, com uma problemática. E o que foi que a gente fez? Pesquisamos, eu e ele". Utilizaram da internet e da criatividade para isso: "A gente foi procurar na internet o que tinha de fogão solar, nós demos uma roupagem diferente do que apresenta na internet. E melhor, demos, além de uma roupagem, uma aplicabilidade que a gente pode transportar ele de forma fácil" (M5).

O último sujeito, M6, respondeu positivamente ao questionamento comentado, dizendo que: [...]todo semestre, eu sempre desenvolvo uma oficina voltada ao conteúdo de sala de aula pra instigar o aluno a procurar se incentivar e se inserir dentro tanto do mercado de trabalho, mas também como dentro das ciências, entende um pouco mais da matemática (M6).

Os dados nos indicaram uma peculiaridade em relação à formação dos sujeitos entrevistados. M1 e M2, não tiveram experiências com pesquisas anteriores à sua prática docente. M1 desenvolveu uma única pesquisa e comenta ter tido algumas dificuldades por ter sido a sua primeira experiência com pesquisa em sala de aula. $\mathrm{O}$ mestrando $\mathrm{M} 2$ não desenvolveu pesquisa com seus alunos. A situação desses dois entrevistados é diferente dos outros quatro, que tiveram algum tipo de relação anterior com a pesquisa. Os entrevistados M3, M4, M5 e M6 possuem a prática da pesquisa em sala de aula presente em suas 
metodologias com inovações nos recursos e percepção de utilização de outros espaços para o desenvolvimento de pesquisa.

\subsection{Aproximações com as Tecnologias Digitais de Informação e Comunicação - TDIC}

A segunda categoria surgiu a partir do questionamento sobre quais instrumentos os mestrandos dispõem para desenvolver trabalhos referentes à iniciação à pesquisa. A entrada das TDIC no espaço escolar acaba por contribuir na modificação dessa estrutura, na medida em que o saber e a informação tornam-se móveis e descentralizados. O docente não é mais o detentor do monopólio do saber, mas sim, como enfatiza Kenski (1998, p. 68), torna-se um parceiro, "um pedagogo, no sentido clássico do termo, que encaminha e orienta o aluno diante das múltiplas possibilidades e formas de se alcançar o conhecimento e de se relacionar com ele". Nesse mesmo sentido, Serres (1994, p. 134) enfatiza que, em termos "etimológicos, a pedagogia significa a viagem da criança em direção às fontes do saber. Até agora existiam lugares de saber, um campus, uma biblioteca, um laboratório [...] Com os novos meios é o saber que viaja".

A partir do exposto, constatamos que o entrevistado M1, ao citar livros, biblioteca, sites e internet, se mantém numa solidez espacial em termos de pesquisa, pois, mesmo visualizando a utilização da internet, o espaço permanece fixo, ou seja, sai de uma territorialidade sala de aula, biblioteca e livros, mas reterritorializa-se no laboratório de informática, não visualizando a internet e o ciberespaço como um território móvel "um espaço que não apenas traz, a qualquer indivíduo situado em um terminal de computador, fluxos ininterruptos e potencialmente infinitos de informação, mas também permite comunicar-se com qualquer outro indivíduo em qualquer outro ponto da esfera terrestre" (SANTAELLA, 2007, p. 177).

Tal afirmação pode ser constatada através das seguintes falas dos entrevistados: “ $A$ gente tem assim, internet nas duas escolas, biblioteca no estado, mas hoje com a internet tu pode realmente dizer para os alunos: olha tu pesquisa nesse, nesse e nesse site. Nesses livros (...) na rede estadual nós temos uma sala de informática” (M1). O entrevistado M2 destacou apenas a internet e o laboratório de informática: "Aqui, é a internet. A minha experiência maior são os laboratórios de informática que existem nas escolas municipais”.

Já M3, destacou os livros e a internet: "Muitos livros e a internet", e também citou o laboratório de informática: "a gente tem duas vezes por semana professor na informática e são só esses dois dias que a gente pode ir pra todas as turmas que tem na escola”. O entrevistado M4, ao utilizar uma rede social para o desenvolvimento de seu trabalho, 
apresenta uma nova perspectiva espacial do saber no que diz respeito à produção da pesquisa e construção do conhecimento: as redes sociais. Conforme M4: "os próprios alunos tiveram uma iniciativa e eles criaram um grupo dentro da rede social do Facebook".

O entrevistado M4 salientou que permite que seus alunos usem o celular para acessar a internet na sala de aula: "Então a internet é o primeiro instrumento que tem facilitado essa comunicação. O uso do celular na aula de Educação Física é permitido". Além disso, comentou sobre o laboratório de informática e da biblioteca: "além do laboratório de informática do instituto, tem um setor responsável que eu posso pegar a chave e levo os alunos até lá, e eles têm acesso à biblioteca também, durante 24 horas, até aos sábados" (M4). Para ele, não é só nesses espaços que a pesquisa acontece, a sala de aula também é trazida: “a pesquisa se faz na sala de aula" (M4). Citou também outros sites: "Os meios sociais, principalmente, o Scielo, o Google acadêmico, e procuro buscar informações com outras pessoas" (M4). E não deixou de fora os livros: "as obras, os livros, eu tenho tido muito acesso no instituto" (M4). Percebe-se claramente que o entrevistado M4 é um professor que orienta TCCs, trabalha com processos de iniciação à pesquisa e também conhece a sistemática da investigação.

Ao permitir a utilização do celular como forma de acesso à internet, M4 demonstra que o computador ou o laboratório de informática não são as únicas formas de acesso ao ciberespaço. Nesse sentido, permite contemplar que, dentro de uma mobilidade social e espacial, o acesso ao ciberespaço se dá por meio de interfaces e navegar "pelas redes informacionais é se aventurar por territórios estrangeiros, travar contatos em busca de conhecimento e engendrar subjetividades" (SANTAELLA, 2007, p. 28).

Constatamos que o entrevistado M4 visualiza diferentes espaços de saber e instrumentos de pesquisa. Utiliza-se desde os mais sólidos instrumentos, tais como livros, sala de aula, biblioteca, laboratório de informática até os líquidos: internet, ciberespaço, redes sociais, sites acadêmicos. Essas informações nos permitem perceber que as ferramentas tecnológicas são uma preocupação junto aos processos de ensino e de aprendizagem do entrevistado M4.

Os entrevistados M5 e M6, além dos instrumentos e espaços até então citados, informaram que utilizam espaços não formais. São espaços tais como o auditório e o Museu de Ciências Naturais (M5). "O museu não é livro pra ensinar, não é um laboratório. Você pode aprender ou não, mas que desperte a curiosidade pra Ciência. Essa é o grande papel" (M5). O entrevistado M6 também falou de outros espaços para utilização na pesquisa: “ $o$ campus nós temos lá na nossa cidade, é... ele é um campo rural como falei, então tem uma 
fazenda de uva, tem uma horta também com vários vegetais, professores trabalham nessa parte" (M6). E, diferentemente do laboratório de informática, enfatizou a utilização do "laboratório de Química que na verdade é laboratório de solos [...] laboratório de processamento" (M6).

Percebe-se que, lentamente, docentes e discentes começam a vislumbrar novos espaços de saber, de construção do conhecimento e de pesquisa, mas, como argumenta Lévy (1994, p. 223), “o espaço do saber está em nascimento constante" e este não surgirá de uma grande noite, mas sim de muitas pequenas manhãs. Espaço este em que o conhecimento está em constante devir, fluido a metamorfosear-se, uma deriva eterna em constante reavaliação, em movimento, pensamentos em estados nascentes. Espaços do saber em que o ensino e a pesquisa gradativamente avançam.

\section{Conclusões}

Tomando como ponto de partida a segunda categoria, que trata da aproximação com as TDIC, percebeu-se que, para os seis entrevistados, o laboratório de informática se apresenta como um espaço de acesso à informação e um recurso para utilização em pesquisa na Educação Básica.

A biblioteca apareceu como um espaço de acesso à informação para quatro dos entrevistados. Este dado nos permite perceber que o livro não é o único ponto de referência do conhecimento, e pode estarperdendo sua hegemonia, já que, a internet é, para os seis mestrandos, o principal acesso à informação nos trabalhos desenvolvidos com seus alunos.

Dentre os sujeitos da pesquisa, três participantes desta, além de comentarem sobre o laboratório de informática e sobre a biblioteca, apresentaram outros espaços e recursos para o desenvolvimento de pesquisas, tais como a sala de aula e a relação direta com projetos da instituição. Constatou-se que estes, já vivenciaram diferentes experiências com pesquisa, e percebem que esta pode ser desenvolvida em mais espaços e tempos. Podemos dizer que há aqui uma desterritorialização, um nomadismo para tratar da construção do conhecimento. Surgiram relatos de outros espaços, como é o caso da investigação em videiras, aparece também uma rede social, a qual é utilizada para contato entre professor e alunos fora do tempo e espaço escolar. No caso dos primeiros entrevistados, o acesso à informação para o desenvolvimento de pesquisa acaba ficando limitado ao espaço e tempo da escola. Porém, em um dos casos, a sala de aula aparece afirmativamente como um bom lugar para se desenvolver as pesquisas.

A questão da iniciação à pesquisa é uma realidade no cotidiano dos entrevistados 
oriundos das regiões Norte, Nordeste e Sul do Brasil, sendo que a compreensão do processo ainda carece de maior discussão e aprofundamento. Todos os entrevistados reconhecem a importância de trabalhar nessa perspectiva, porém, não há consenso sobre o modo como tal se efetive, haja vista o fato de que os espaços formais, especialmente o laboratório de informática, ainda concentram grande parte da atenção dos professores, especialmente no que tange os processos de ensino e de aprendizagem, em tempos de TDIC.

\section{Referências}

BOGDAN, R. e BIKLEN, S. Investigação qualitativa em educação: uma introdução à teoria e aos métodos. Porto, Editora Porto, 1994.

KENSKI, V. M. Novas tecnologias: o redimensionamento do espaço e do tempo e os impactos no trabalho docente. Trabalho apresentado na XX Reunião Anual da ANPED, Caxambu, Setembro de 1997. Publicado em Maio, Junho, Julho e Agosto de 1998, nº , p. 5871.

LÉVY, P. A inteligência coletiva: para uma antropologia do ciberespaço. Portugal: Instituto Piaget, 1994.

Ed. 34, 2001.

. A conexão planetária: o mercado, o ciberespaço, a consciência. São Paulo:

MORAES, R. e GALIAZZI, M. C. Análise textual discursiva. Ijuí: Editora Unijuí, 2013.

MORAES, R.; GALIAZZI, M.C. e RAMOS, M. Pesquisa em sala de aula: fundamentos e pressupostos (In.) MORAES, Roque e LIMA, Valderez Marina do Rosário( Orgs.)Pesquisa em sala de aula: tendência para a educação em novos tempos.3.ed.Porto Alegre:

EDIPUCRS,2012, p.11-20.

PESAVENTO, S. J. Fronteiras da história: uma leitura sensível do tempo. In: SCHÜLER, F., et.al. (Orgs) Fronteiras do pensamento: retratos de um mundo complexo. São Leopoldo: Ed. UNISINOS, 2008, pp. 179-190.

RIO GRANDE DO SUL. Secretaria da Educação. Proposta pedagógica para Ensino Médio Politécnico e Educação Integrada ao Ensino Médio 2011-2014.Disponível em:<http://educacao.rs.gov.br/dados/ensmedproposta.pdf> Acesso em: 24 de julho de 2013.

SANTAELLA, L. Linguagens Liquidas na era da mobilidade. São Paulo: Paulus, 2007.

SERRES, M. Atlas. Portugal: Instituto Piaget, 1994. 